\title{
TRANSGLYCOSYLATION ACTIVITY AND CHARACTERIZATION OF RECOMBINANT SUCROSE PHOSPHORYLASE FROM LEUCONOSTOC MESENTEROIDES MBFWRS-3(1) EXPRESSED IN ESCHERICHIA COLI
}

\author{
EDITHA RENESTEEN, FURQON DWI CAHYO, AMARILA MALIK*
}

Department of Pharmacy, Division of Pharmaceutical Microbiology and Biotechnology, Faculty of Pharmacy, Universitas Indonesia, Depok, Indonesia. Email: amarila.malik@ui.ac.id

Received: 30 September 2019, Revised and Accepted: 23 December 2019

\begin{abstract}
Objective: Sucrose phosphorylase (SPase) is an enzyme that catalyzes the transfer of glucosyl to various acceptor molecules. Distinct types of SPases have been reported, and their transglycosylase activities have been shown to differ. In general, glycosylation is a process that is used to modify bioactive compounds. As such, glycosylation can increase the chemical stability of compounds and improve their characteristics such as reduce strong smell and sour taste. We previously cloned recombinant SPase (SPaseWRS-3[1]) from Leuconostoc mesenteroides MBFWRS-3[1] in Escherichia coli. In the current study, we aimed to characterize SPaseWRS-3 and determine its transglycosylation activity using benzoic acid (BA), ascorbic acid, and kojic acid (KA).
\end{abstract}

Methods: Expression analyses were conducted in lysogeny broth (LB) medium supplemented with tetracycline and expression was induced using isopropyl- $\beta$-d-thiogalactopyranoside. The characteristics of the $56 \mathrm{kDa}$ recombinant SPase (rec-SPase) were confirmed using sodium dodecyl sulfate polyacrylamide gel electrophoresis (SDS-PAGE). Rec-SPase activity was determined spectrophotometrically using sucrose as the substrate and NADPH as the end-product at $340 \mathrm{~nm}$. Transglycosylation activity was evaluated using thin-layer chromatography (TLC) on silica gel plates.

Results: Our results demonstrated that the rec-SPase had an activity of $98.52 \%$ relative to the reference SPase (ref-SPase). BA and KA were determined to undergo glucosyl transfer by rec-SPase using ref-SPase, as observed with TLC. Our findings are consistent with those reported previously for the SPase isolated from L. mesenteroides.

Conclusion: Recombinant SPase activity is comparable to reference SPase activity. Our study could be the initial study to deeply observe SPase activity in other substrates as well.

Keywords: Escherichia coli, Kojic acid, Benzoic acid, Ascorbic acid, Leuconostoc mesenteroides, Sucrose phosphorylase.

(c) 2020 The Authors. Published by Innovare Academic Sciences Pvt Ltd. This is an open access article under the CC BY license (http://creativecommons. org/licenses/by/4. 0/) DOI: http://dx.doi.org/10.22159/ijap.2020.v12s1.FF058

\section{INTRODUCTION}

Sucrose phosphorylase (SPase) is an enzyme that catalyzes glycosylation reactions such as the reversible catalysis of sucrose and inorganic phosphate to $\alpha$-D-glucose-1-phosphate (G-1-P) and D-fructose, a reaction that has been widely utilized in industry for decades [1]. In this reaction, the SPase enzyme transfers the glucosyl section of G-1-P and sucrose to various acceptor molecules, which are used in the manufacture of both food and cosmetic materials. For example, these biologically active compounds can be used as drug precursors and/ or converters of other biologically active compounds to improve their characteristics. As such, glycosylation can neutralize the occurrence of a strong smell, sour taste, or low solubility [2,3].

SPases have been found in several bacteria, including lactic acid bacteria (LAB) classified as generally recognized as safe such as Bifidobacterium lactis [4,5], Leuconostoc mesenteroides [6-8], Bifidobacterium longum $[9,10]$, and Oenococcus oeni [11]. Recently, SPase has become the focus of increasing research interest due to its ability to generate intermediate drug precursors. Despite the broad acceptor specificity of the enzyme, differences in enzyme specificities among bacterial species have been reported.

The activity of SPase from L. mesenteroides has been used in a variety of industrial applications, including to transfer the glucosyl moiety of G-1-P to various sugars and sugar alcohols [12], to transfer the glucosyl moiety of sucrose to phenolic or alcoholic hydroxide groups of various substances [12-16], and to transfer the glucosyl moiety of sucrose or of G-1-P to acceptors such as galactose, maltose, and glucose or beta linkage compounds such as cellobiose and gentiobiose using sucrose as a glucosyl donor to produce various acceptor reaction products [17]. Because LAB is considered safe for humans, the production of enzymes in some species for food- and health-related industrial applications is highly promising. For example, the formation of 2-O-a-D-glucopyranosyl-L-ascorbic acid (AA-2G) from AA plays an important role in maintaining skin elasticity and in repairing damaged skin compared with AA [18]. Moreover, the derivative of this enzyme sucrose $6^{\mathrm{F}}$-phosphate phosphorylase has provided a novel insight into the human gut microbiome [19].

In the previous studies [20], we screened, identified, and cloned the SPase gene from L. mesenteroides MBFWRS-3(1), which was isolated from a sugar-containing beverage from Solo, Indonesia. SPaseWRS-3(1) from the indigenous Indonesian LAB was found to have a $99 \%$ amino acid sequence similarity to an existing enzyme, 1355SPase [20]. Accordingly, this previous study provided valuable information on the molecular diversity of bacterial SPases, particularly with respect to their unique transglycosylation characteristics and the SPase recombinants.

In this study, we aimed to produce recombinant SPaseWRS-3(1) on a large scale and study the transglycosylation activity of recombinant SPaseWRS-3(1) using the substrates benzoic acid (BA) and AA. In addition, rec-SPase activity was measured using sucrose as a substrate, with the measurement of NADPH as the end-product at $340 \mathrm{~nm}$. 
Transglycosylation activity assays were conducted using thin-layer chromatography (TLC) with acetonitrile + water and butanol + acetic acid + water as the mobile phase on silica gel plates. Our results revealed that the best glucosyl transfer reaction activities of rec-SPase and ref-SPase were obtained using BA ( $\mathrm{Rf}=0.55)$, which was able to produce lower Rf $(0.15-0.2)$ substances, as observed on the TLC plate.

\section{MATERIALS AND METHODS}

\section{Materials}

The SPase gene was cloned from L. mesenteroides MBFWRS-3(1) into the plasmid pAM-SPWRS-3(1) followed by transformation into Escherichia coli BL-21 Star ${ }^{\mathrm{TM}}$ (pAM_SPaseWRS3), as previously described [20].

\section{Protein expression and purification of recombinant SPase}

A single colony of E. coli BL-21 Star ${ }^{\mathrm{TM}}$, carrying the recombinant plasmid pAM_SPaseWRS-3(1), was inoculated into $5 \mathrm{~mL}$ of LB medium containing $5 \mu \mathrm{g} / \mathrm{mL}$ tetracycline and incubated overnight under shaking conditions at $37^{\circ} \mathrm{C}$. The culture was then inoculated into $500 \mathrm{~mL}$ of $\mathrm{LB}$ medium until the $\mathrm{OD}_{600}$ reached 0.2 . Subsequently, $500 \mu \mathrm{L}$ of $5 \mu \mathrm{g} / \mathrm{mL}$ tetracycline was added and the culture was incubated with shaking at $200 \mathrm{rpm}$ at $37^{\circ} \mathrm{C}$ for $1 \mathrm{~h}$. Protein expression was induced by the addition of $500 \mu \mathrm{L} 1 \mathrm{mM}$ isopropyl- $\beta$-d-thiogalactopyranoside (Wako, Japan) followed by additional incubation at $37^{\circ} \mathrm{C}$ with shaking. Fermentation was continued at $30^{\circ} \mathrm{C}$ for $2 \mathrm{~h}$. The cells were then collected by centrifugation $\left(15,000 \times \mathrm{g}, 10 \mathrm{~min}, 4^{\circ} \mathrm{C}\right)$, suspended in phosphate buffer ( $50 \mathrm{mM}, \mathrm{pH}$ 6.8), and disrupted by ultrasonication for $15 \mathrm{~min}$ (Branson Sonifier, England). The enzyme was harvested by centrifugation $(6000 \times$ $g$ at $4^{\circ} \mathrm{C}$ for $10 \mathrm{~min}$ ).

Ni-NTA affinity chromatography was then used to purify $6 \times$ His-tagged recombinant SPase ( $1 \mathrm{~mL}$, His SpinTrap; GE Healthcare, Germany). The purified C-terminal 12-histidyl tagged protein was collected by elution with $500 \mathrm{mM}$ of imidazole buffer $(20 \mathrm{mM}$ sodium phosphate, $500 \mathrm{mM}$ $\mathrm{NaCl}$, and $500 \mathrm{mM}$ imidazole at a $\mathrm{pH}$ of 7.4) at a flow rate of $1 \mathrm{~mL} / \mathrm{min}$. The molecular mass of the recombinant SPaseWRS-3(1) obtained was determined using the Laemmli system (Laemmli 1990) using a 10\% acrylamide (BioRad, USA) gel. Proteins were stained with Coomassie Blue R-250 (BioRad).

\section{Enzyme activity assay and protein content quantification}

SPase activity was measured using a modified method of Silverstein [1,18]. Briefly, the standard assay involved the usage of $60 \mathrm{mM}$ potassium phosphate buffer ( $\mathrm{pH}$ 6.4), $0.14 \mathrm{M}$ sucrose, $0.09 \mathrm{mM}$ EDTA-Na ${ }_{2}, 0.36 \mathrm{mM} \mathrm{NADP}{ }^{+}, 0.003 \mathrm{mM}$ d-glucose-1,6-diphosphate, $15 \mathrm{mM} \mathrm{MgCl}_{2}, 6$ units $\alpha$-phosphoglucomutase $\mathrm{mL}^{-1}$, and 6 units glucose6-phosphate dehydrogenase $\mathrm{mL}^{-1}$. The reaction mixture was then incubated under five different $\mathrm{pH}$ conditions ( $\mathrm{pH} \mathrm{5}, 6,7,7.5$, and 8) at five different temperatures $\left(25^{\circ} \mathrm{C}, 30^{\circ} \mathrm{C}, 35^{\circ} \mathrm{C}, 37^{\circ} \mathrm{C}\right.$, and $\left.40^{\circ} \mathrm{C}\right)$. The increase in absorbance was measured using a spectrophotometer at $340 \mathrm{~nm}$.

One unit of SPase activity was defined as the amount of enzyme that released $1 \mu \mathrm{mol} \mathrm{NADP}{ }^{+} \mathrm{min}^{-1}$. An SPase standard (0.5 units) from L. mesenteroides (Oriental Yeast, Co., Ltd., Japan) was used as the positive control, whereas sterile water was used as the negative control. Protein concentration was measured according to the Bradford method (1976), with bovine serum albumin (Fermentas, USA) as the standard.

Transglycosylation activity assay with BA, AA, and kojic acid (KA) Transglucosylation of $\mathrm{BA}$ was conducted in water containing $0.4 \%$ BA and $20 \%$ sucrose at pH 5.1. Two units of SPase were added to the mixture and the reaction mixture was incubated at $37^{\circ} \mathrm{C}$ for $16 \mathrm{~h}$. The reaction product was then analyzed by TLC using acetonitrile + water (70:30) as the mobile phase on silica gel plates. The spot resulting from TLC was detected at $254 \mathrm{~nm}$ [3].

Transglucosylation of AA was performed in $100 \mathrm{mM}$ HEPES buffer at pH 7.5 containing $0.5 \%(\mathrm{w} / \mathrm{v}) \mathrm{AA}$ and $30 \%(\mathrm{w} / \mathrm{v})$ sucrose. The reaction mixture containing $20 \mu \mathrm{L}$ of HEPES buffer and 0.2 unit/ $\mu \mathrm{L}$ SPase was then incubated at $37^{\circ} \mathrm{C}$ for $15 \mathrm{~h}$. The reaction was stopped by the elimination of SPase with an Ultrafree-MC (10,000 NMWL, Millipore, USA). The reaction product was analyzed by TLC using butanol + acetic acid + water (3:1:1) as the mobile phase on silica gel plates [2]

Transglucosylation of KA was performed with a reaction volume of $10 \mathrm{~mL}$ at pH 7.5; the reaction mixture contained 0.4 units of recombinant SPaseWRS-3(1), $200 \mu \mathrm{g}$ KA (Nacalai Tesque, Japan), 0.1 M phosphate buffer, and $30 \%$ sucrose. The reaction was incubated at $37^{\circ} \mathrm{C}$ for 7,8 , 12 , and $24 \mathrm{~h}$. The reaction was stopped by the elimination of SPase with Centricon (10,000 NMWL cut-off, Millipore, USA). The reaction product was analyzed using TLC-densitometry with acetonitrile and $\mathrm{dH}_{2} \mathrm{O}$ $(80: 20)$ as the mobile phase and silica gel plates as the solid phase. Peaks were detected at an absorbance of $254 \mathrm{~nm}$ by a TLC scanner.

\section{RESULTS AND DISCUSSION}

\section{Recombinant SPaseWRS-3(1) protein confirmation}

We evaluated the overexpression of recombinant SPase from E. coli BL$21 \mathrm{Star}^{\mathrm{TM}}$, and purification of the protein was achieved using 12-histidyl residues, which were fused to the $\mathrm{C}$-terminal end of the protein during construction. The purified SPases from the E. coli lysates appeared as a dominant single band slightly $<66 \mathrm{kDa}$ (Fig. 1) on SDS-PAGE and with Coomassie Brilliant Blue staining. This is consistent with the predicted molecular mass of $57 \mathrm{kDa}$ that has been reported previously [20]. After purification and desalting, it was determined that the BL-21 Star ${ }^{\mathrm{TM}}$ recombinant could be produced at a high yield and exhibited high activity compared with ref-SPase ( $98 \%$ of the SPase reference activity), as shown in Fig. 2. The optimum temperature for activity was $37^{\circ} \mathrm{C}$, whereas the optimum $\mathrm{pH}$ was found to be 7 , with an SPase recombinant concentration of $1117.5 \mu \mathrm{g} / \mathrm{mL}$.

SPase from L. mesenteroides has been researched for several decades [6,7]. Although these SPases are produced from the same species (L. mesenteroides), the C-terminal region sequences of L. mesenteroides SPases have been found to be different depending upon the source. It is assumed that the diversity in sucrose-related genes and their products in different bacteria is responsible for this.

Although three potential catalytic amino acid residues, namely, Asp196, Glu-237, and Asp-295, are located in the conserved sequences of the $L$. mesenteroides SPases, there exists some dissent on the diversity of the transglycosylation properties of SPases with respect to the acceptors and their products $[2,17,21,22]$. This variability could be due to the involvement of the C-terminal region. Thus, different protein structures may exist, as indicated by different transglycosylation yields and acceptor efficiencies.

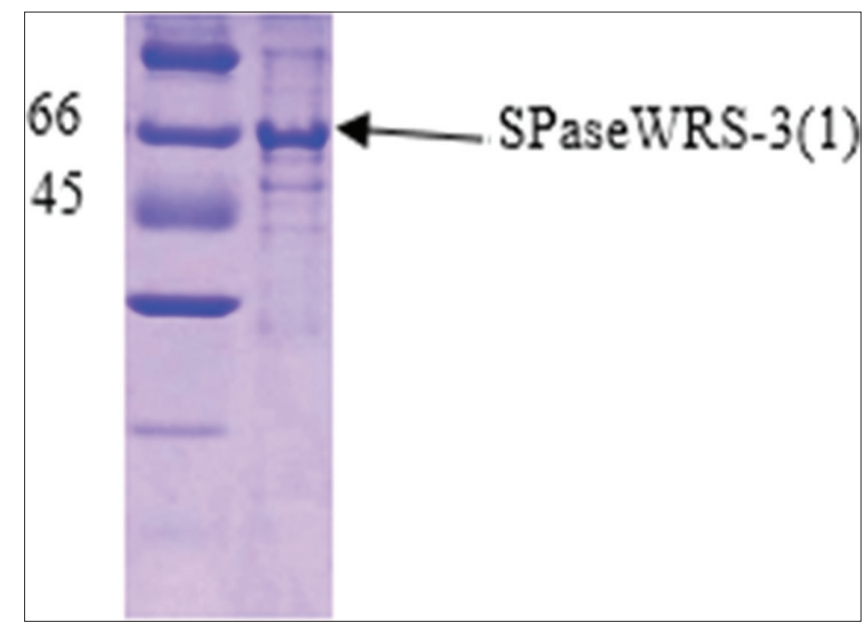

Fig. 1: SDS-PAGE analysis of purified recombinant sucrose phosphorylase produced by Escherichia coli BL21 STAR ${ }^{\mathrm{TM}}$ 


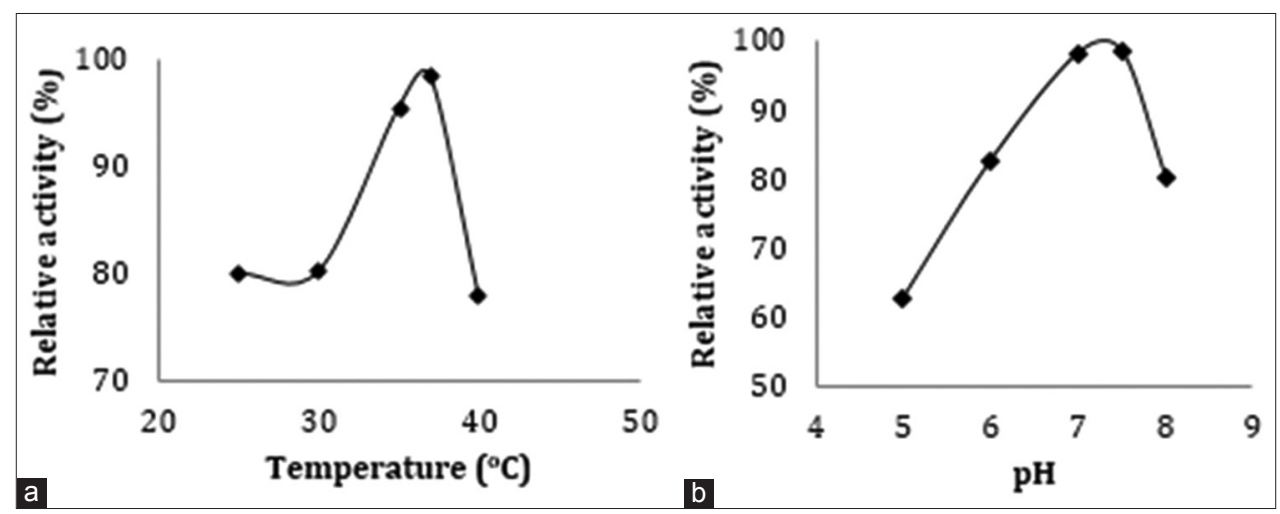

Fig. 2: Relative activity of SPaseWRS-3(1) against the SPase reference at different temperatures (a) and pH values (b)

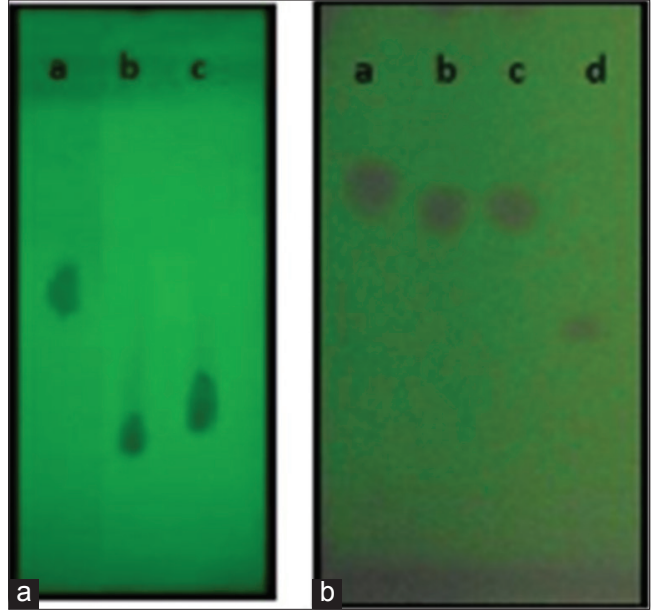

Fig. 3: Thin-layer chromatography analysis of benzoic acid (BA) (Rf 0.55). (a), Reaction of BA with the SPase standard (Rf $0.15)$; (b), reaction of $B A$ with the SPase recombinant ( $R f 0.2$ ); (c), acetonitrile + water (70:30) as the mobile phase on silica gel plates A. TLC analysis of ascorbic acid (AA) (Rf 0.75) (a), reaction of AA with SPase standard (Rf 0.72); (b), reaction of AA with SPase recombinant (Rf 0.72); (c), AA2G (Rf 0.5); (d) using butanol + acetic acid + water (3:1:1) as the mobile phase on silica gel plates $B$

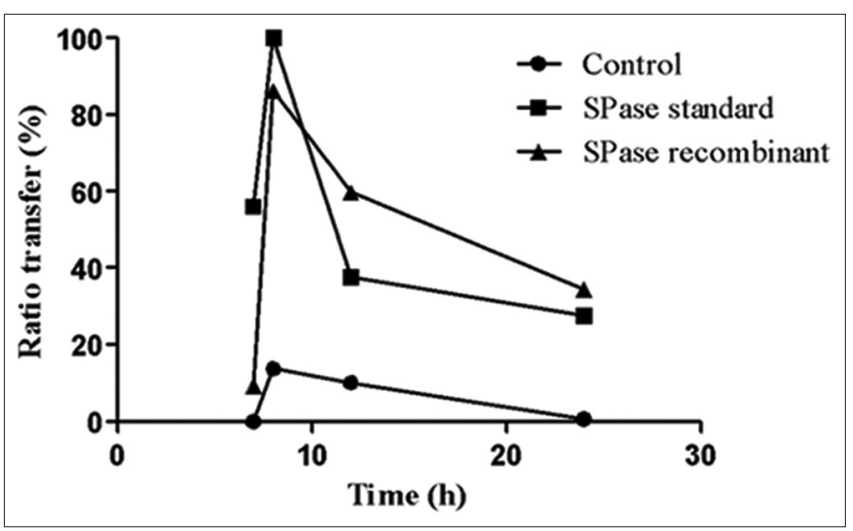

Fig. 4: Ratio of the transfer of kojic acid over time

The strain of $L$. mesenteroides, from which the SPase is sourced, may affect the structure of the gene and lead to different yields. The strain MBFWRS-3(1) was isolated from Wedang Ronde, a popular hot Javanese dessert containing glutinous rice balls stuffed with peanut paste floating in a hot sweet ginger and lemongrass tea. In this case, the sample was obtained from the liquid portion, which contains a mixture of brown and regular sugar. The strain MBFWRS-3(1) was then confirmed as L. mesenteroides by $16 \mathrm{~S} \mathrm{rDNA}$ analysis [23].

\begin{abstract}
Transglycosylation activity
Transglycosylation activity assays demonstrated that the highest glucosyl transfer reaction activities of rec-SPase and ref-SPase were obtained using BA (Rf 0.55), which produced lower Rf (0.15-0.2) substances, as observed on the TLC plates (Fig. 3a). In contrast, AA did not show activity because the Rf values of the reactions of AA with the SPase standard or with the recombinant enzyme did not differ (Fig. 3b). For KA, transglycosylation activity was shown because there was movement of the substances based on the Rf values. However, the separation was minimal.
\end{abstract}

The conversion of KA to KA transglycosylate increased over time over the $8 \mathrm{~h}$ period (Fig. 4). Subsequently, the reaction reversed, producing KA after $24 \mathrm{~h}$. These results are in line with those of previous studies because the transglycosylation reaction was reversible $[12,18,2]$. The differences in the transglycosylation activity of KA with SPase-rec, which has a ratio probability of only $86 \%$, maybe due to the diversity of the SPase enzyme. Indeed, Malik et al. (2011) studied amino acid residue variations in SPase-rec (SPaseWRS-3(1)) from L. mesenteroides and found differences of approximately 16\% [20]. This variability likely impacts the protein structure, resulting in decreased affinity for substrates and changes in enzyme flexibility. Collectively, these factors are believed to underlie the diversity of the enzyme.

SPase from L. mesenteroides has shown transglycosylation activity with BA, particularly under acidic conditions [24]. Moreover, SPase from $L$. mesenteroides reportedly cannot transfer the glucosyl moiety of sucrose to BA at pH 7.5 [10]. However, the enzyme is reported to catalyze the transglucosylation reaction to $\mathrm{BA}$ at $\mathrm{pH} 5$ [24]. The results of these studies are consistent with those of the current study, which showed the presence of transglycosylation activity when analyzed using TLC.

To stabilize AA, particularly under thermal and oxidative conditions, the derivative AA2G is produced through transglycosylation activity. This new substance is extremely stable in vitro and exhibits AA activity in vivo after enzymatic hydrolysis to $\mathrm{AA}$ by $\alpha$-glucosidase $[25,26]$. During the process of AA phosphorolysis, SPase catalyzes the transfer of the glucosyl moiety of sucrose to G-1-P and D-fructose, a reaction which is reversible [12]. The transglucosylation activity of AA has previously been demonstrated by Kwon et al. (2007) using SPase-rec from B. longum. They detected the major product using HPLC and confirmed the presence of AA2G using LC-MS/MS [2]. However, the results of our study did not reveal any product from this enzymatic reaction. This is likely because the rec-SPase used in the current study was produced from L. mesenteroides and had different properties compared with the enzymes derived from other bacteria. Moreover, another previous study has demonstrated than an optimum $\mathrm{pH}$ of 5.2 could selectively catalyze 
SPase to convert sucrose to AA2G with high efficiency and perfect selectivity in B. longum [27]. Our results are consistent with those of a previous study conducted by Kitao and Sekine (1992) in which they did not find an AA glucosylation reaction.

\section{CONCLUSION}

In this study, we successfully produced recombinant SPase on a large scale from E. coli BL-21 Star ${ }^{\mathrm{TM}}$, with a molecular weight of approximately 45-66 kDa and relative activity of approximately 98\%. The activity of recombinant SPase is comparable to that of reference SPase. The best glucosyl transfer reaction activities of rec-SPase and ref-SPase were achieved using BA ( $\mathrm{Rf}=0.55)$, which produced low $\mathrm{Rf}(0.15-0.2)$ substances, as observed by TLC. Additional quantitative assays using HPLC and BA to ensure the activity of the transglucosylation product are warranted. Our study could be the initial study to deeply observe SPase activity in other substrates as well.

\section{ACKNOWLEDGMENTS}

This work was supported by Research Grants: Universitas Indonesia Research Grant for International Collaboration 2011-2012 to AM and Hibah PDUPT 2018-2019 (no. 261/UN2.R3.1/HKP.05.00/2018 and NKB-1469/UN2.R3.1/HKP.05.00/2019) from the Ministry of Research, Technology and Higher Education Republic of Indonesia to AM.

\section{CONFLICTS OF INTEREST STATEMENT}

All authors declare no conflicts of interest to declare in this project.

\section{REFERENCES}

1. Silverstein R, Voet J, Reed D, Abeles RH. Purification and mechanism of action of sucrose phosphorylase. J Biol Chem 1967;242:1338-46.

2. Kwon T, Kim CT, Lee JH. Transglucosylation of ascorbic acid to ascorbic acid 2-glucoside by a recombinant sucrose phosphorylase from Bifidobacterium longum. Biotechnol Lett 2007;29:611-5.

3. Nomura K, Sugimoto K, Nishiura H, Ohdan K, Nishimura T, Hayashi H, et al. Glucosylation of acetic acid by sucrose phosphorylase. Biosci Biotechnol Biochem 2008;72:82-7.

4. Kim M, Kwon T, Lee HJ, Kim KH, Chung DK, Ji GE, et al. Cloning and expression of sucrose phosphorylase gene from Bifidobacterium longum in E. coli and characterization of the recombinant enzyme. Biotechnol Lett 2003;25:1211-7.

5. Gore S, Paul A, Bhagwat Y. Comparative evaluation of commercially available probiotics products. Int J Curr Pharm Sci 2017;9:26-30.

6. Koga T, Nakamura K, Shirokane Y, Mizusawa K, Kitao S, Kikuchi M. Purification and some properties of sucrose phosphorylase from Leuconostoc mesenteroides. Agric Biol Chem 1991;55:1805-10.

7. Kawasaki H, Nakamura N, Ohmori M, Sakai T. Cloning and expression in Escherichia coli of sucrose phosphorylase gene from Leuconostoc mesenteroides No. 165. Biosci Biotechnol Biochem 1996;60:322-4.

8. Kitao S, Nakano E. Cloning of the sucrose phosphorylase gene from Leuconostoc mesenteroides and its overexpression using a 'sleeper' bacteriophage vector. J Ferment Bioeng 1992;73:179-84.

9. Kitaoka M, Hayashi K. Carbohydrate-processing phosphorolytic enzymes. Trends Glycosci Glycotechnol 2002;14:35-50.
10. Zhang H, Sun X, Li W, Li T, Li S, Kitaoka M. Expression and characterization of recombinant sucrose phosphorylase. Protein $\mathrm{J}$ 2018;37:93-100.

11. Bharti V, Mehta A, Singh S, Jain N, Ahirwal L, Mehta S. Bacteriocin: A novel approach for preservation of food. Int J Pharm Pharm Sci 2015;7:20-9.

12. Kitao S, Sekine H. $\alpha$-D-glucosyl transfer to phenolic compounds by sucrose phosphorylase from Leuconostoc mesenteroides and production of $\alpha$-arbutin. Biosci Biotechnol Biochem 1994;58:38-42.

13. Kitao S, Sekine H. Syntheses of two kojic acid glucosides with sucrose phosphorylase from Leuconostoc mesenteroides. Biosci Biotechnol Biochem 1994:58:419-20.

14. Kitao S, Ariga T, Matsudo T, Sekine H. The syntheses of catechinglucosides by transglycosylation with Leuconostoc mesenteroides sucrose phosphorylase. Biosci Biotechnol Biochem 1993;57:2010-5.

15. Kitao S, Matsudo T, Saitoh M, Horiuchi T, Sekine H. Enzymatic syntheses of two stable (-)-epigallocatechin gallate-glucosides by sucrose phosphorylase. Biosci Biotechnol Biochem 1995;59:2167-9.

16. Kitao S, Matsudo T, Sasaki T, Koga T, Kawamura M. Enzymatic synthesis of stable, odorless, and powdered furanome glucosides by sucrose phosphorylase. Biosci Biotechnol Biochem 2000;64:134-41.

17. Lee JH, Moon YH, Kim N, Kim YM, Kang HK, Jung JY, et al. Cloning and expression of the sucrose phosphorylase gene from Leuconostoc mesenteroides in Escherichia coli. Biotechnol Lett 2008;30:749-54.

18. Li Z, Han H, Wang B, Gao J, Zhu B, Peng R, et al. Transglucosylation of ascorbic acid to ascorbic acid 2-glucoside by a truncated version of a-glucosidase from Aspergillus niger. J Food Biochem 2017;41:e12432.

19. Tauzin AS, Bruel L, Laville E, Nicoletti C, Navarro D, Henrissat B, et al. Sucrose $6^{\mathrm{F}}$-phosphate phosphorylase: A novel insight in the human gut microbiome. Microb Genom 2019;5:1-14.

20. Malik A, Ishikawa S, Sahlan M, Ogasawara N, Nguyen UQ, Suryadi H. Screening for sucrose phosphorylase in exopolysaccharide producinglactic acid bacteria reveals spasewrs-3(1) in Leuconostoc mesenteroides isolated from sugar containing-beverage 'wedang ronde' from Indonesia. Afr J Biotechnol 2011;10:16915-23.

21. Abada EA, Osman ME, Lee JH, Kim D. Molecular cloning of the gene 1355spase encoding a sucrose phosphorylase from the bacterium Leuconostoc mesenteroides B-1355. Biotechnology 2008;7:463-8.

22. Van Den Broek LA, Van Boxtel EL, Kievit RP, Verhoef R, Beldman G, Voragen AG. Physico-chemical and transglucosylation properties of recombinant sucrose phosphorylase from Bifidobacterium adolescentis DSM20083. Appl Microbiol Biotechnol 2004;65:219-27.

23. Malik A, Radji M, Kralj S, Dijkhuizen L. Screening of lactic acid bacteria from Indonesia reveals glucansucrase and fructansucrase genes in two different Weissella confusa strains from soya. FEMS Microbiol Lett 2009;300:131-8

24. Sugimoto K, Nomura K, Nishiura H, Ohdan K, Ohdan K, Hayashi H, et al. Novel transglucosylating reaction of sucrose phosphorylase to carboxylic compounds such as benzoic acid. J Biosci Bioeng 2007;104:22-9.

25. Wakamiya H, Suzuki E, Yamamoto I, Akiba M, Otsuka M, Arakawa N. Vitamin C activity of 2-O-alpha-D-glucopyranosyl-L-ascorbic acid in Guinea pigs. J Nutr Sci Vitaminol (Tokyo) 1992;38:235-45.

26. Wakamiya H, Suzuki E, Yamamoto I, Akiba M, Arakawa N. In situ intestinal absorption of 2-O-alpha-D-glucopyranosyl-L-ascorbic acid in Guinea pigs. J Nutr Sci Vitaminol (Tokyo) 1995;41:265-72.

27. Gudiminchi RK, Nidetzky B. Walking a fine line with sucrose phosphorylase: Efficient single-step biocatalytic production ofl-ascorbic acid 2-glucoside from sucrose. Chembiochem 2017;18:1387-90. 